\title{
Linguoculture of Social Networks in the Internet Galaxy: Horizontal and Vertical Outlook
}

\author{
Irina V. Fotiyeva*, Elena V. Lukashevich, Tamara A. Semilet, Vladimir V. Vitvinchuk, \\ ${ }^{1}$ Altai State University, 656049, Altai Territory, Lenin av, 61, Barnaul, Russia, fotieva@ bk.ru
}

\begin{abstract}
Relying on theoretical background (philosophical, cultural, communicative, and linguistic concepts) and the empirical study of communication within such social networks as YouTube, Instagram and Facebook, the authors substantiate the advent and development of new cultures existing in the Internet Galaxy, i.e. linguocultures of social networks, in modern digital and masscommunication community. These new phenomena represent autonomous, high-quality standard and valuable communicative systems appearing on digital network platforms, which are characterized by particular linguistic and communicative aspects: symbolic tools of public communication, standards of verbal behavior, communication formats, principles of self-organization and self-reproduction. The authors also emphasize the autonomy of new cultures thus highlighting the intervention from social institutes of power and business to ensure social control and management, which, therefore, results in both horizontal and vertical dimensions of linguocultures within social networks. Taking the above into account the authors forecast alternative options related to the future of new cultures.
\end{abstract}

\section{Introduction}

The concepts proposed by M. Castells on the Internet Galaxy as a new communicative space; A. Toffler and M. McLuhan on a demiurgical role of technology in sociocultural life; developers of the theory of social networks on a domineering role of horizontal communications over vertical ones in modern society; N. Lumann's pan-communication theory of social systems; O. Spengler on culture as a "uniform stylistics" were further confirmed by the formation of new cultural phenomena, namely linguocultures of social networks and their carriers, i.e. communicative network communities.

At present, many literature sources are devoted to the analysis of social networks, including the history of their interdisciplinary study (Borgatti\&all, 2009), mechanisms of identity construction within social networks (Jones, Volpe, 2011), mathematical methods of their simulation (Wasserman\&all, 1994), etc.

At the same time, the study of various aspects related to this topic is only in its initial stage, especially when linguocultures of social networks are still in progress and are influenced by all kinds of factors. Thus, the empirical study of various technical tools of communication, methods of conveying a message, language, formats, genres, formal and informal norms of public messages, communicative strategy and tactics of social network users, for instance YouTube content in comparison with Instagram and Facebook, as well as the analysis of sociocultural content of new cultures, delimitation of their sovereignty and methods of intervention from economic and political communities.

\section{Theoretical background of linguocultures within the range of the Internet social networks}

According to M. Castells, the introduction of digital technologies into social life led to the appearance of a special field of sociocultural community and the formation of a new level being the virtual reality or the Internet Galaxy. He emphasizes that the recent years of the second millennium are characterized by the explosion of the Internet as the system of communication and organizational structure (Castells, 2001). In fact, the statistics shows that the capacity of digital electronic space and time spent by users are constantly growing. We Are Social and Hootsuite revealed that as of the beginning of 2018, the number of the Internet users in 2018 reached 4 billion people, and according to GlobalWebIndex, the average Internet user today spends approximately 6 hours per day in the Internet (Digital in 2018, 2018). Moreover, there is a steady growth of such indicators every year.

The virtual reality completes former already existing structures of society (economic, political, social, cultural), changes their real operation into online mode (Semilet\&all, 2017). However, conceptually new structures - social networks were also formed within this galaxy, which formed the basis for reformatting of a global sociocultural environment of the present thus creating new virtual and communicative areas of distribution throughout the planet. The social networks also foster the formation and active functioning of linguocultural communicative communities. 
While traditional cultures were based on territorial, national, and religious integration, the new digital cultures of the Internet are determined, first of all by technical and communicative features of social networks, thereby implementing the fundamental postulate of technical determinism (A. Toffler, M. McLuhan, etc.), which indicates that the development of engineering and technology causes fundamental changes in life of people and society as a whole.

It also should be admitted that social-media networks in communication existed before: "...Social networks form the integral feature of human relations in principle. All mechanisms of social networks are initially embedded into the communication practice" (Fil, 2016). Yet today the social network is mainly understood as a: a) virtual, b) communicative, c) horizontal, d) self-organized network. Such understanding fits within the theory of a "network community" developed by Jan van Dijk (van Dijk, 2001), M. Castells (Castells, 1996), B. Wellman (Wellman, 1996) and some other authors whereby in modern society the social networks begin to gain their predominant role in relation to communications within institutional, governmental and political, social and stratification, corporate and other structural entities.

The social network embodies the N. Lumann's pancommunication theory, which implies that nowadays communication serves the main substrate and the basic factor of the society: "The social system is a set of networks, and therefore spatial boundaries merely reflect the inner structuring of a system, its internal differentiation aimed to overcome its complexity and the surrounding environment. The issue of a subject and an object can easily be solved since the system creates its own descriptions, where each communication implies self-description" (Lumann, 2004, 15). According to this, the self-reference system, though depending on the surrounding world and unable to exist without it, is not determined by it and hence "is able to organize and build its own order" thereby "creating structures of a system through its own system processes" (Lumann, 2017). Network communication forms a new type of linguocultures, which correspond to O. Spengler's postulate that the culture as a unit of the global space "may be defined as a $<\ldots>$ certain uniform stylistics" (Spengler, 2018).

Thus, the linguocultures of social networks within the Internet represent autonomous, high-quality standard and valuable communicative systems appearing on digital platforms of network channels, which are characterized by particular linguistic and communicative aspects (stylistic peculiarity): symbolic tools of public communication, standards of verbal behavior and norms of public messages, communication formats, speech strategies and tactics, principles of self-organization and self-reproduction.

The common features of new linguocultures include mediation through digital technologies, virtuality, selfpresentation, interactivity, hypertextuality, creativity and rhizome. These cultures exist within the Internet Galaxy, represent the symbolic sphere where the reality is created through symbols and images, their carriers are focused on public self-expression and feedback; the text is normally simulated by references to other fragments of information space, the main value of a message is its originality; there are multiple independent centers of distribution and accumulation of information.

\section{Empirical study of linguocultural identity of social networks within the Internet}

Along with their common features, linguocultures of various social networks have their peculiarities: each of them has its own features of language, genre, norm and communicative strategy.

The programmed structure and functionality of social networks determine spatiotemporal and genre parameters of public communication.

Social networks do not simply become a communicative platform, they turn into spatiotemporal cultural matrixes, and a resource of self-expression and self-identification. The indisputable leader in this field is the Facebook, which in early 2018 accounted to nearly 2.17 billion registered profiles. The age of the most active users of this network falls within the range from 18 to 44 years. Arguably, the algorithms and procedure of Facebook administration exert a great influence over communicative genres, create the feeling of egoism and behavior model of billions of users who are in the age of the maximum social activity. Facebook forms a universal linguoculture since it provides all users with a steady easy-to-master communication tool kit and certain communicative genres.

If Facebook, provided different types of media are used, is mainly focused on text creation, then the Instagram is fully aimed at visual communication. Any post within this network shall be followed by an image; texts, as a rule, serve as comments to the image and are limited in volume (earlier the video duration made not more than 15 seconds, but in 2016 this parameter was increased 4 times). Thus, Instagram implies the production of compressed visual messages and superficial consumption through "sliding" along the news feed. It is not fortuitous that taking into account all national and religious flair of his media identity, when getting to Instagram Ramzan Kadyrov becomes a typical popular user completely accepting the rules of virtual life.

One of the most popular social networks producing new linguocultures is YouTube. In 2017, the number of users of this social network in some degree and partly a video hosting exceeded 1.5 billion people. In Russia $63 \%$ of the Internet users regularly resort to services of YouTube (according to We Are Social and Hootsuite). This network offers its users an opportunity to consume or make content only in one format - as videos but in different genres spontaneously created by network opinion leaders.

The LiveDune allows assessing the popularity of YouTube content in different countries. The analysis of the most popular channels of this video hosting in the USA, Germany, Russia, Kazakhstan, Ukraine, Belarus and Georgia shows that a certain set of communicative genres and strategies is typical for all countries where the citizens are engaged into global visual communication. The language, genres and communicative strategies being elements of YouTube linguoculture are formed against the network fashion and informal rules set by popular bloggers - new charismatic and creative opinion leaders and millions of subscribers.

The PewDiePie channel in the USA (https://www.youtube.com/channel/UC- 
1HJZR3Gqxm24_Vd_AJ5Yw), having over 61 million subscribers, may be considered as a world pattern and an example to follow. The manner of creative activity of the blogger creating the content under this nickname and his genre preferences are copied by dozens of the most popular bloggers from different countries: SOBOLEV, LARIN, Danila Poperechny (Russia), Andrey Martynenko, Sergey Tracer (Ukraine), Temnaya FAZA, Islam Badurgov (Kazakhstan), A4, Masterildar (Belarus), LeFloid (Germany), Andrey Vodonaev (Georgia), Nigahiga, Logan Paul (USA). All these bloggers use approximately identical set of YouTube genres in different variety when they create any video content: pranks, provocations, rap clips, rap satire, traveling, pseudo-sensations, simplified animation, everyday life, unpacking, reactions to something, conflicts with other bloggers, social content or charity.

For example, when in early 2018 the Logan Paul's channel was blocked because he posted a video of a suicide victim in Japan, the blogger began to make socially-oriented videos devoted to suicide prevention.

It is remarkable that among its top five channels the Russian YouTube includes the English-speaking blog VitalyzdTv (https://www.youtube.com/channel/UC1KPy3c AAj0i0RIFC SzjMg) operated in Florida by a Russian-born Vitaly Zdorovetskiy. First of all, he works in the genres of pranks and charity showing, among others, the moment he fulfilled a former homeless man's dream to procure a new set of teeth in Florida.

The developed set of genres and communicative strategies of digital culture provokes new users of the Internet Galaxy to use the suggested tools. For example, Leonid Parfenov who created his Parfenon in YouTube (https://www.youtube.com/channel/UCbhMGG0ZievPtK8m zLH5jhQ) in February, 2018 demonstrates effective integration of popular bloggers into community using already typical genres for the Internet users: review of wines, traveling, emotions, filming using a selfie stick, etc.

For the entire international blogger community, a critical and at the same time very typical tool of creating a video content is delegation of emotions and messages in cases when the author of a YouTube channel pastes a fragment from any movie, telecast or a video content of other bloggers to better emphasize some idea or a thought. For instance, to emphasize his contempt towards another popular blogger Paul Logan, PewDiePie in his clip "Can this video hit 1 million likes" (https://www.youtube.com/watch?v=hHR9aM494rs) pasted a scene from The Avengers where one of the characters Hulk beats his opponent Tor. The Russian followers such as Evgeny Bazhenov in his BadComedian (https://www.youtube.com/channel

/UC6cqazSR6CnVMClY0bJI0Lg) often pastes unsuccessful scenes from Alexander Nevsky's movies to emphasize his irony, contempt, etc. Besides other elements, the political blogger Dmitry Ivanov in his kamikadzedead channel (https://www.youtube.com/channel/UCDbsY8C1eQJ5t6

KBv9ds-ag) often uses scenes from Bazhenov's videos or George Carlin's speeches.

A striking example of this growing tendency may be the use of such tools by the Russian politician Alexei Navalny. In the investigation clip "Yachts, oligarchs, girls: men huntress discloses corruption" (https://www.youtube.com/watch?v= $\underline{\mathrm{RQZr} 2 \mathrm{NgKPiU}}$ ) to express the attitude towards the words of
Nastya Rybka the author used a scene from the Gangs of New York where the "Bill the Butcher" Cutting says a phrase "What on earth are you talking about?".

Thus, it is possible to conclude that language, communicative genres, formal and informal norms, communicative strategies acquired by billions of users of social networks are on the one hand, created by the user license agreement, technical and communicative format and algorithms of social networks, which may be recognized as the genesis of formal rules of digital linguoculture. On the other hand, the specified parameters are spontaneously formed by network opinion leaders who define informal rules within social networks. The developed linguocultures eliminate territorial, national and religious distinctions, thus becoming global and universal cultural communities.

\section{Conditions of network linguocultural sovereignty. Intervention from economic and political institutes of society}

Currently, communicative linguocultures are mostly considered as autonomous, self-sufficient and decentered. The network virtual space forms a new type of sociality, transition to exterritorial social networks and opportunity to form them independently. "Within a network society a personality ... is given additional opportunities for selective expansion of social environment,... can form personal social world in compliance with projects, interests and preferences" (Nestik, 2016). M. Castells calls this a network individualism.

The growing efficiency, mobility and flexibility of communication ensures the transition towards more diverse forms of organization of various fields of human activity. M. Castells summarizes: "A theory based on the concept of a social structure, built on dynamic networks, breaks with the two reductionist metaphors on which sociology was historically based: mechanical view of society as a machine made up of institutions and organizations; and the organicist view of society as a body, integrated with organs with specific bodily functions. Instead, if we need a new metaphor, sociology of the network society would be built on the selfgenerating processes discovered by molecular biology, as cells evolve and develop through their interaction of networks, within the body and with their environment. Interactive networks are the components of social structure, as well as the agencies of social change. The sociology of the network society may be able to bridge structure and practice in the same analytical grasp" (Castells, 2000: 697-698).

It is typical to compare a network model of decentralized network society with the concept of rhizome by Gilles Deleuze and Felix Guattari: "The basic principle underlying the rhizome concept is communication and heterogeneity". It implies that each point of a rhizome can be connected with any other point: the rhizome has no initial point of development, it is decentralized and antihierarchical. In other words, neither of its points shall have competitive advantage similar to the fact that there cannot be any privileged communication between two separate points. G. Deleuze and F. Guattari oppose closed and centered systems of machines or organisms to opened and decentered rhizomatic varieties" (Nazarchuk, 2008: 62-66). 
In fact, linguocommunicative network space with signs of freedom, independence, stochastic character of habitualization of communicative practices is more and more exposed to intervention from institutionalized spheres of society. In recent years, this global tendency is noted in a number of works with a particular focus in two leading spheres: economy (business) and politics.

Thus, V.V. Buryak and I.V. Kravchenko write about the evidence of economic development of the Internet and social networks. The book by Clara Shih "The Facebook Era: Tapping Online Social Networks to Build Better Products, Reach New Audience, and Sell More Stuff' allows understanding specifics of the Internet and guarantees "bonuses" to those individuals who took the risk of their financial and social investments into this unpredictable emerging sector of the "future economy" (Buryak, Kravchenko, 2014: 220).

The huge block of materials is devoted to the study of marketing technologies based on network resources. "Social networks provide the opportunity to talk with customers on a personal level, which is usually difficult to achieve or impossible through traditional channels. Marketing on social networking sites isn't a substitute for traditional marketing. It should be treated as an additional channel with unique characteristics that can complement other marketing activities. With this approach, we can increase the effectiveness of each channel" (Assaad, Gómez, 2011: 15).

The former Google Design Ethicist Tristan Harris released a number of materials devoted to the Internet methods impacting the consciousness of potential consumers within network and to methods of counteracting such "business attacks". In particular, he emphasizes: "The western culture is based on ideals of individual choice and freedom. Millions from us furiously protect the right to make a "free" choice thus ignoring situations when the choice is limited to options, which were not initially chosen" (Harris, 2017).

D.A. Gubanov, et al. in their heuristic work devoted to mathematical models of network management summarize the following: "Social networks ... are increasingly becoming objects and means of information management and the arena of information confrontation" (Gubanov\&all, 2010:16).

Similarly, in politics these processes are not more obviously revealed. A.A. Svinyin notes that social networks become new points of growth in the development of a company brand and in interactions between political institutes and citizens. "The growth of audience, high involvement of social networks users in comparison with traditional web resources ... attract the attention of politicians around the world to this Internet technology as to the tool used to influence people during the election campaigns" (Svinin, 2013: 158). He gives two indicative examples. First, according to experts, the election campaign of Barack Obama was successful only due to social network technologies, and, second, the election campaign of the president of France in 2012 (Svinin, 2013: 160-161). R.A. Pupykin also writes about this tendency identifying Vkontakte.com and Facebook as resources having the most considerable manipulative potential (Pupykin, 2013: 22).

Summarizing these tendencies, A.-M. Slaughter highlights horizontal (not hierarchical, self-organized) and vertical (hierarchical, centralized and manageable) social networks (Slaughter, 2004: 19). In modern virtual space the competition of these two forms of development of social networks and, hence, linguocultures formed on their basis is possible.

Researchers note that in recent decades the political structures seize the most diverse manipulative technologies that include a variety of linguo-psychological influence: actualization, transformation or formation of mental and mythological constructs; actualization of valuable and emotional representations; management of information space; involvement of psychological automatic actions; use of psychological and convincing logical tricks (Dzyaloshinsky, 2012).

\section{Examples of communicative strategies and tactics of political structures within social networks}

In Russia the indicative example of intervention of political structures of a society into linguocultures of social networks through hidden impact on consciousness of users in order to impose a certain opinion and estimates favorable to politicians and to create the relevant thematic communities is the online movement "For Vladimir Putin!" presented on the corresponding portal in Facebook (https://www.facebook.com/for.vladimir.putin/). It is noteworthy that over two million people around the world are signed for this source, working languages are Russian, English, Ukrainian, Spanish, Suomi, there are also comments in Arab.

Let us consider the page stories for March, 2018 covering the significant event for the country: Russian presidential elections.

Since the native speakers join the discussion as members of social groups, then relations between various groups are important for a discourse. The analyzed materials clearly shows the difference between "insiders" and "outsiders" defined in relation to a key figure V.V. Putin as the current president of Russia, as the candidate for presidency, and as the best world leader. Besides, there is an obvious semantic shift in the attitude of users of this resource: "Strong president - strong Russia". For a communicative effect of the "presidential elections" the "insiders" group includes the following: V.V. Putin campaign headquarters; all Russians voting for Putin (for the strong country/Russia); representatives of the global community from the USA, Europe, Algeria, Egypt, etc.; famous Russian athletes, musicians, singers, actors, officials, etc.

The hashtag in these materials serves not only the filter of simple and convenient search of defined topics or their groups, but also the concentrated expression of psychological background uniting the "insiders": \#WorldSupportsPutin; \#StrongCountry \#elections2018, etc. The videos devoted to these events show visualized correlation of the specified notions.

The general constructive attitude of this communicative format should also be noted: authors of texts, photos, and videos don't focus on "outsiders". Perhaps, such emphasis is partially traced only in the genre of comments: "outsiders" oppose the president but don't make any efforts, etc. 
All elements of multimedia history "For Vladimir Putin!" are built around the personality of V.V. Putin as the key actor of all communicative events requiring some attention to his personality for any purpose.

Thus, more than fifteen hundred active and dynamic pictures taken at different times do not merely depict certain social actions of V.V. Putin as a state official, but show the "transition from anonymity to presentation of prestigious personality engaged in communication but not simply conveying a message" (Leontiev, 3008: 72). The genre is marked as "Chronicles": Putin - a wise, reflecting, explaining, speaking with people on equal terms "without a piece of paper", open communicator; Putin is a strict, uncompromising leader; Putin in an ice-hole for the Epiphany, in a church for Christmas and Easter; Putin in sports equipment on a hockey rink or a tatami; Putin in his office, at the piano, in fishing, in a cabin of the jet plane, etc. All these demonstrate Putin' features so sympathetic to a typical Russian. This results in the image of a communicator required for specific purposes (complementary presentation).

It is worth noting videos independently. In total, since 1 January 2018 approximately 18 videos are presented on the portal, 12 of which have less than a hundred thousand views [https://www.facebook.com/pg/for.vladimir.putin/videos/? ref=page_internal].

The authors analyzed communicative strategies and tactics in three videos with the biggest number of visits: 1) fourteen-second advertising video of the International Federation of Association Football (FIFA): 100 DAYS TO GO - FIFA WORLD CUP RUSSIA 2018 - 3.4 million views (6.03.2018); 2) twenty-nine-second video: Athletic President!!! - a fragment of an interview to Match TV channel - 477 thousand views (13.03.2018); 3) one and a half minute video: Congratulations on the Defender of the Fatherland Day! - 276 thousand views (23.02.2018).

A. Polonsky fairly notes that the mass media concept, "on the one hand, is turned to reality, to practice of its understanding by society, and on the other hand, to ideology setting the focus, importance and evaluation of certain facts, events, notions, setting parameters of cognitive activity of a person" (Polonsky, 2012: 53).

Thus, in the initial FIFA video the famous football players of 32 countries, participants of the FIFA World Cup, juggle the balls, and at the end of a clip the President of Russia Vladimir Putin and the FIFA president Gianni Infantino join them. They symbolize the corporate status of the FIFA World Cup. The main communicative strategy of the full version is to advertise "the greatest show on earth". The short version of the video presented on "For Vladimir Putin!" shifts the focus towards V. Putin and G. Infantino who "are able to compete with the legendary players in playing football" [https://russian.rt.com/sport/video/489164-putin-chekanitmyach-fif]. Given that the majority of users do not identify the FIFA president, the main focus is on the President of Russia. Hence, the strategy of self-presentation is implemented with public image perfection of V. Putin.

It is important to note that the visual content does not come along with the verbal one. Putin and Infantino wearing formal business suits, although their jackets being unbuttoned, pass each other the football, which obviously destroys a stereotype of a bureaucratic official and implies positive evaluation and even a praise. This leads to a complementary image of "our" president who is able to professionally manage everything, including a ball. The heading of the full version of the video posted in Facebook and YouTube is "100 DAYS TO GO - FIFA WORLD CUP RUSSIA 2018: Putin and Infantino juggle a ball in the FIFA video"

[https://www.facebook.com/RTRussian/videos/1632240390 227346/; https://www.youtube.com/watch? $\mathrm{v}=\mathrm{WABgDQOfxAM}$. "To juggle" is a professional jargon, which means a certain and basic way of juggling for a football player, when "the one juggling doesn't let the ball fall down by throwing it up with legs, a breast, shoulders and a head" [https://dic.academic.ru/dic.nsf/ruwiki/1675005]. Moreover, the communicative tactics of cooperation with famous world football players causes emotional shift of their positive features towards V. Putin.

In the second video "Athletic President!!!" we see V. Putin demonstrating his great physical condition within twenty-nine seconds. Dynamic change of shots with the corresponding background music without any verbal text, a rhythm, movements of the main character who is professionally boxing, riding a horse, sending a puck to the opponent's gate, swimming in a fast-flowing mountain river, surviving the duel on tatami, professionally skiing down a mountain, etc. allow improving the status and role of V. Putin by influencing the users' emotions. As a result, over thirty thousand people put likes under this video, and the most frequent comments are \#WorldSupportsPutin; Athletic President! Athletic President! [https://www.facebook.com/for.vladimir.putin/videos/17184 31358243403/].

Considering that the video was posted in Facebook on 13 March 2018, i.e. just before the Russian presidential elections, then its advertising focus is obvious alongside with the tactics of taking the initiative, implicit confrontation in relation to other candidates in the election race with the emphasis on the image of modern Russia "Strong president strong country".

The change of the main communicative strategy becomes more noticeable if in comparison with the two-year-old video when sport for V. Putin was positioned as "not a game but the guarantee of health of the nation" [https://www.facebook.com/for.vladimir.putin/videos/96509 6140243599/].

The third video differs fundamentally from the previous ones since it is focused on the event having particular importance for Russians - Congratulations on the Defender of the Fatherland Day. Therefore, scenes showing new Russian weapon (tanks, planes, rockets, air defense systems, etc.), participation of Russian military troops in various defense operations, modernization of military manpower training, ceremonial military parade on the Red Square are followed by congratulations of the Russian President to military personnel, civilians employed in the armed forces, veterans of various wars [https://www.facebook.com/for.vladimir.putin/videos/16981 92220267317/].

The main communicative strategy is cooperative and interactive, including for non-Russian-speaking users (word for word translation into English is provided). Putin uses the strategy of cooperation with the "insiders" and the hidden confrontation with potential enemies, where the confrontation 
is implemented in communicative tactics of warning, prevention, appealing not only to minds of potential opponents, but also to feelings which is supported by a rhetorical strategy: "The Russian army is one of the leading armies of the world"; "The objective of military service is readiness to sacrifice yourself for the sake of the compatriots. There are many people like that in Russia".

All the above demonstrates active intervention of political structures of society in linguocultures of social networks by using manipulative practices and open agitation.

This poses a question: whether linguocultures of social networks will maintain their sovereignty in the Internet Galaxy or will they turn into a new powerful tool of manipulation from the structures dominating in offlinesociety? The answer lays in the future. By paraphrasing J. Ortega y Gasset it is possible to conclude that "The question mark is typical for our era, it is rather huge in size and ambiguous in form and it is still not clear whether it represents a triumphal arch, a guillotine or a scaffold ..." (Ortega y Gasset, 2017).

\section{Conclusions}

The conducted study provides for a number of conclusions.

1. There is enough theoretical ground to confirm that in the new sphere of sociocultural reality - the Internet Galaxy - a new type of cultures is formed on the basis of technical and communicative aspects: linguocultures of social networks reformatting global cultural space by overcoming boundaries of states and areas of traditional cultures. The common features of new linguocultures include mediation through digital technologies, virtuality, self-presentation, interactivity, hypertextuality, creativity and rhizome; communication based on principles of antihierarchy and decentralization, freedom of expression and communicative behavior.

2. Along with other common features, linguocultures of different social networks have their peculiarities expressed in languages, genres, formats, norms and communicative strategies, which makes them unique thus identifying them as autonomous high-quality cultures of a new type. The empirical study showed that the structure and functions of social networks determine spatial-temporal and genre parameters of public communication, while norms, formats, communicative strategies are formed either spontaneously or under the influence of the opinions leaders.

3. Traditional social institutes make attempts to influence horizontal (not hierarchical, self-organized) linguocultures of social networks in order to include them into vertical (hierarchical, centralized and operated) networks, which represents diversion against principles of freedom and independence of communication, their antihierarchy and decentralization, violation of their sovereignty.

4. As a result of confrontation between "horizontal" and "vertical" aspects the linguocultures of social networks reached their bifurcation point: they may become either areas of free communication aimed at creativity, mutual informational and emotional treatment or turn into channels of manipulative impact on consciousness for the benefit of economic and political structures.

\section{References}

1. W. Assaad, J. M. Gómezб International Journal of Managing Public Sector Information and Communication Technologies (IJMPICT) 1, 2, 13-22 (2011).

2. S. P. Borgatti, A. Mehra, D.J. Brass, G. Labianca. Science 323 (5916), 892-895 (2009).

3. V. V. Buryak, I.V. Kravchenko, Scientific notes of the Tavrida National University, named by V.I. Vernadsky. Series Philosophy. Culturology. Political science. Sociology 27 (66), 217-223 (2014)

4. M. Castells, The Internet Galaxy: Reflections on the Internet, Business and Society (Oxford, Oxford University Press, 2001).

5. M. Castells, Contemporary Sociology 5, 29, 693-699 (2000).

6. M. Castells, The Information Age: Economy, Society and Culture. Vol. I: The Rise of the Network Society (Cambridge, Oxford, Blackwell Publishers, 1996)

7. Digital in 2018: World's internet users pass the 4 billion mark (2018). URL:

https://wearesocial.com/blog/2018/01/global-digitalreport-2018» (date of access: 03.03.2018).

8. I. M. Dzyaloshinsky, Communicative impact: targets, strategies, technologies (Moscow, NIU HSE, 2012)

9. M. S. Fil. Social networks. New technologies for managing the world (Moscow, Synergy, 2016).

10. D. A. Gubanov, D. A. Novikov, A. G. Chkhartishvili. Social networks: models of information influence, management and confrontation (Moscow, Publishing house of physical and mathematical literature, 2010)

11. T. Harris How technology manipulates our mind. URL: http://www.iidf.ru/media/articles/lifehacks/kaktekhnologii-manipuliruyut-nashim-razumompopulyarnye-tryuki-priyemy-i-fokusy/ (date of access: 12.02.2018)

12. G. M. Johannes van Dijk, De Netwerkmaatschappij, Sociale aspecten van nieuwe media (Alphen a/d Rijn, Samsom, 2001)

13. C. Jones, E.H. Volpe, Journal of Organizational Behavior 32, 413-434 (2011)

14. A.A. Leontiev, Applied psycholinguistics of speech communication and mass (Moscow, Sense, 2008)

15. Lumann N. Society as a social system (Moscow, Publishing house "Logos", 2004)

16. N.Lumann Social systems: an outline of the general theory. URL: http://lib.znate.ru/docs/index-17728.html (date of access: 15.11.2017)

17. A.V. Nazarchuk, Issues of Philosophy 7, 61-75 (2008)

18. T. Nestik, Intellectual networks: from network individualism to creative capital. Site of S.P. Kurdyumov. URL: http://spkurdyumov.ru/networks/intellektualnye-seti-otsetevogo-individualizma-k-tvorcheskomukapitalu/20.03.2016 (date of access: 22.03.2018) 
19. J. Ortega Gasset, The revolt of the masses. URL: http://rumagic.com/ru_zar/sci_philosophy/ortega-igasset/6/j1.html (date of access: 23.11.2017)

20. A.Polonsky, Contemporary Discourse Analysis 6, 42-56 (2012)

21. R.A. Pupykin, Economic and humanitarian studies of regions 1, 19-26 (2013)

22. T.A. Semilet, V.V. Vitvinchuk, A.R. Golubeva., Philosophy and Culture. 11, 10-19 (2017)

23. A.-M. Slaughter, A New World Order (Princeton and Oxford, Princeton University Press, 2004).

24. O. Spengler, The Decline of the West. URL: http://az.lib.ru/s/shpengler_o/text_1922_zakat_evropy.s html (date of access: 12.03.2018)

25. A.A. Svinin, Using social networks as Internet technologies in election campaigns, the international experience. Bulletin of the RUDN, Series of Political Science, 2, 157-163 (2013)

26. S. Wasserman, K. Faust, Social Network Analysis in the Social and Behavioral Sciences. Social Network Analysis: Methods and Applications (University Press, Cambridge, 1994)

27. B. Wellman, An Electronic Group is Virtually a Social Network. In: S. Kiesler (Ed.) Research Milestones on the Information Highway (Hillsdale, Lawrence Erlbaum, 1996) 